\title{
Thermal modelling of earth air heat exchanger (EAHE) and analyse of health risk
}

\author{
Geoffroy Chardome ${ }^{1}$, Véronique Feldheim ${ }^{1}$ \\ ${ }^{1}$ UMONS - Faculté Polytechnique - Service Thermique et Combustion, Rue de l'Épargne, 56 - \\ 7000 Mons - Belgique
}

\begin{abstract}
This study characterizes the amount (volume) and the temperature of the condensates obtained in an Earth-toAir Heat Exchanger in Belgium (EAHE) to define if this particular biotope is propitious to the development of pathogenic microorganisms. Different numerical models of an EAHE have been developed and the results validated with experimental measurements. The total condensate produced in the model of EAHE studied was $25.22 \mathrm{~kg}$ in 2015 and $56.59 \mathrm{~kg}$ in 2016. Most of the condensation appears during June, July and August. The air temperatures at the outlet of the EAHE are quite close to the temperature of the condensates produced. These temperatures are between $3^{\circ} \mathrm{C}$ and $23^{\circ} \mathrm{C}$, it is very conducive to the development of psychrophilic microorganisms.
\end{abstract}

\section{Introduction}

The EAHE is an old ventilation technique already used in Iran in 3000 BCE (Ozgener, 2011; Jomehzadeh, 2017).

The aim of this study is to characterize the amount (volume) and the temperature of the condensates obtained in an Earth-to-Air Heat Exchanger or EAHE. We have developed different numerical models of EAHE and validated them with experimental measurements over a period of one year using a time step of one hour. To limit the calculation time needed to study the unsteady 3D configuration, a pseudo-3D model was used to determine the temperature field and the flows exchanged.

The studied EAHE consists of two horizontally buried pipes at an average depth of $1.625 \mathrm{~m}$. The air used in the hygienic ventilation of the building is blown through these pipes. They allow the preheating of the ventilation air in winter and the passive cooling in summer thanks to the thermal capacity of the earth (Bordoloi, 2018). However, this technique can decrease the indoor air quality by microorganisms in contact with the condensate present in the EAHE. The characterization of these condensates may define if this particular biotope is propitious to the development of pathogenic microorganisms, even though the filtration system of ventilation seems sufficient to stop a significant part of the microorganisms (Déoux, 2011; Barbat, 2012).

The EAHE models often neglect latent heat transfer. These are negligible when the interest consists in the energetic potential of this technique. Our proposed model considers these transfers and quantifies them. Many studies have analysed the indoor air quality in buildings considering its impact on the health and productivity of the occupant (Fisk, 2002; Wargocki, 2011). The objective was to reduce the ventilation rates to limit the energy consumption of the buildings while maintaining air quality at acceptable levels. The most studied pollutants are radon, physical agents (PM2.5, PM10, moisture content) and chemical agents (VOCs, PAHs, CO2, etc.). The biological agents are not considered because these are difficult to analyse. Without considering biological pollutants, an EAHE normally installed to ensure ventilation flows, improves indoor air quality. The present study focuses on the health risk associated with this EAHE.

\section{Experimental setup and results \\ Installation studied}

The installation is located on the site of the Technical Campus of the 'Haute École en Hainaut' (HEH) in Mons, Belgium. Its scheme is given in Figure 1.

The EAHE is made of HDPE (High Density Polyethylene) and consists in a suction element associated with a vertical shaft with a diameter of $375 \mathrm{~mm}$ which sinks into the ground to a depth of $1.25 \mathrm{~m}$. It is then divided into two pipes each having an inside diameter of $140 \mathrm{~mm}$ and forming an angle to ensure a distance of $1 \mathrm{~m}$ between them and thus to prevent one pipe from influencing the temperature of the soil around the second pipe. A slope of $3 \%$ ensures the evacuation of the condensates.

Given the EAHE layout, the pipes form a $90^{\circ}$ angle before joining into a vertical output EAHE having a depth of 2 $\mathrm{m}$, a diameter of $375 \mathrm{~mm}$ and in which the condensates are removed using a pump. Once the air comes out of this vertical shaft, it enters the building's crawl space through a fully insulated pipe (to reduce the heat losses) and is then sucked by a controlled mechanical ventilation system with heat recovery, which pulses this air in a control room. It should be noted that the depth of the installation is not optimal. The EAHE is expected to have an average depth of about $2.25 \mathrm{~m}$, while the installation was conducted at an average depth of $1.625 \mathrm{~m}$. The soil temperature therefore varies more during the year and the potential for cooling in summer and preheating in winter is reduced. It is the presence of the water table that has imposed the limitation of the depth of the EAHE, because although the water and the radon tightness of this one is ensured by 
heat-shrink sleeves, it was technically difficult to dig below the level of the water table. The presence of the latter nevertheless has a positive effect, as it promotes the exchanges between the EAHE and the soil.

Air circulation in the EAHE is provided by a mechanical ventilation system located therein. The thermal losses of the fans have no impact on the air's outlet temperatures of the EAHE. The air flow circulating in the EAHE is 250 $\mathrm{m}^{3} \cdot \mathrm{h}^{-1}$, so we consider that an air flow of $125 \mathrm{~m}^{3} \cdot \mathrm{h}^{-1}$ circulates inside each pipe.

\section{Measurement system}

The installation represented on Figure 1 is equipped with waterproof and shielded thermocouples to prevent any measurement error due to the condensation on the thermocouple. More details on thermocouples are included in conference paper (Chardome, 2018). It is possible to measure the temperature of the ground, of the outside air, in different places of the EAHE and obviously at the exit of the EAHE itself.

A thermocouple of type ' $\mathrm{T}$ ' is composed of copper and constantan (copper and nickel alloy). Its accuracy is very important, and the absolute error is of the order of $0.1^{\circ} \mathrm{C}$.

\section{Type of soil studied}

Given the completion of a geotechnical campaign, due to the works related to the pipeline of a nearby river, the depth of the water table and the soil composition at the EAHE level are known (INISMa, 2011) although it is composed of backfill for historical reasons.

The water table is at a depth of $2.5 \mathrm{~m}$ and the nature of the soil is a non-plastic brown sandy-stony backfill type whose characteristics, represented on the Table 1, are as follows:

Table 1: Physical characteristics of the soil.

\begin{tabular}{|c|c|c|c|}
\hline $\begin{array}{c}c \\
\mathrm{~J} \cdot \mathrm{kg}^{-1} \cdot \mathrm{K}^{-1}\end{array}$ & $\begin{array}{c}\rho \\
\mathrm{kg} \cdot \mathrm{m}^{-3}\end{array}$ & $\begin{array}{c}k \\
\mathrm{~W} \cdot \mathrm{m}^{-1} \cdot \mathrm{K}^{-1}\end{array}$ & $\varepsilon$ \\
\hline 1000 & 1800 & 0,58 & 0,95 \\
\hline
\end{tabular}

\section{Experimental results}

Every 15 minutes, the measuring system records the outside temperature, the soil temperature at $2 \mathrm{~m}$ depth, the temperatures in each pipe every $5 \mathrm{~m}$ and the temperature at the output of the EAHE. To limit the simulation data, an average of the measurements has been made to get hourly values.

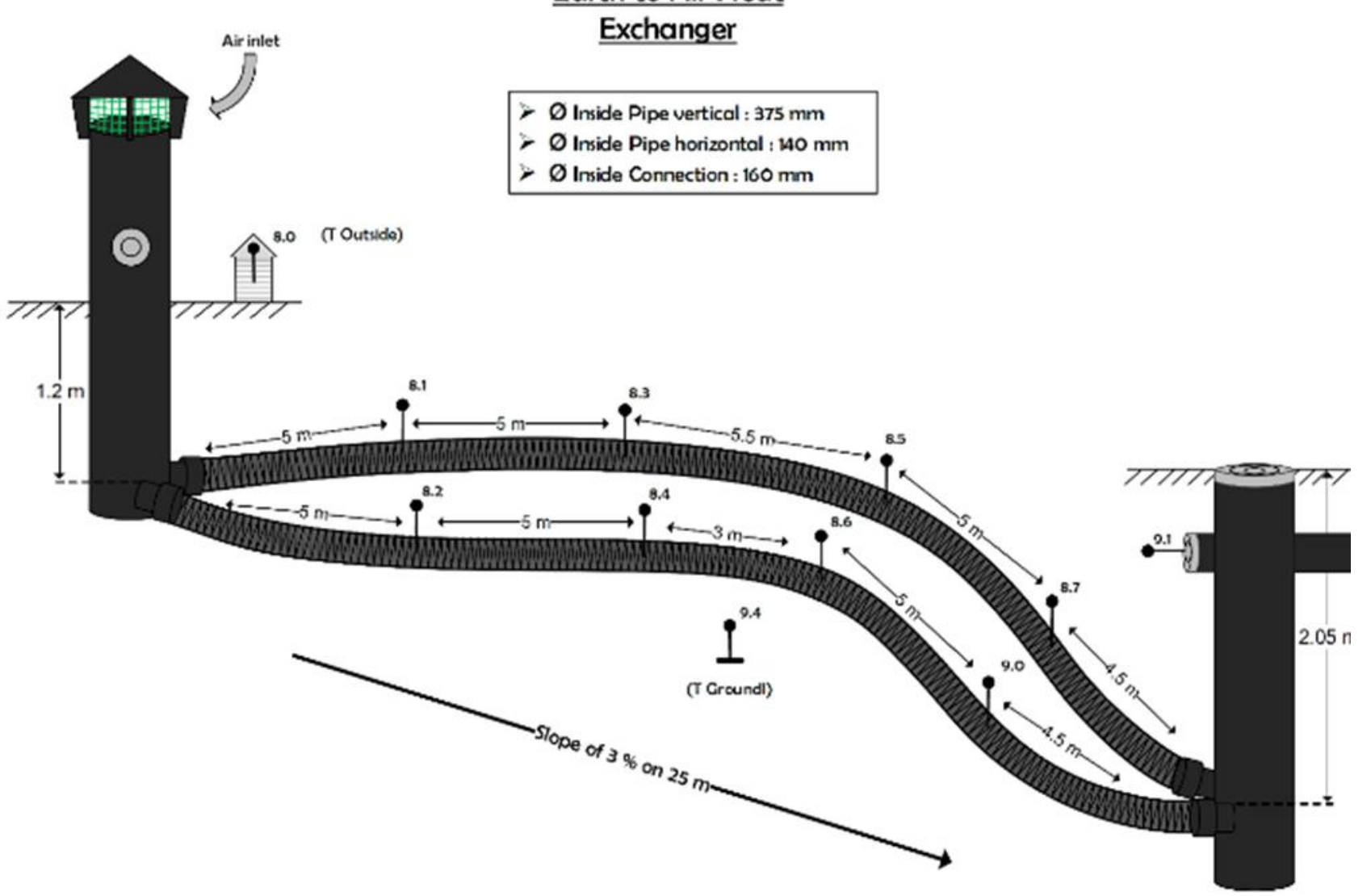

Figure 1 Scheme of the monitored installation and location of the thermocouples

The EAHE is monitored since June 2014 and the simulations are made for the years 2015 and 2016. In order to limit the impact of the choice of the initial values in the numerical models, for year 2015 on Figure 2, the readings start on 01 December 2014 at 01:00 am, which corresponds to the time - 743. January 01, 2015 at 00: 00 $\mathrm{h}$ is taken as a reference at 0 o'clock and January 01, 2016 at 00: 00 o'clock corresponds to the time 8760. For 2016 on Figure 3, the readings start on 01 December 2015 at 01:00 am, which corresponds to the time - 743. January 01,2016 at $00: 00 \mathrm{~h}$ is taken as a reference at 0 o'clock 
and January 01, 2017 at 00: 00 o'clock corresponds to the time 8784 because it is a leap year.

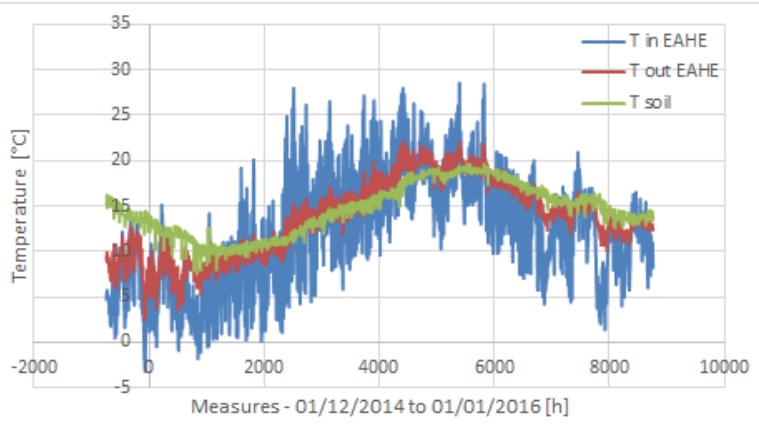

Figure 2: Soil temperature measured at $2 m$ depth and EAHE inlet and outlet temperatures during the period from 01/12/2014 to 01/01/2016.

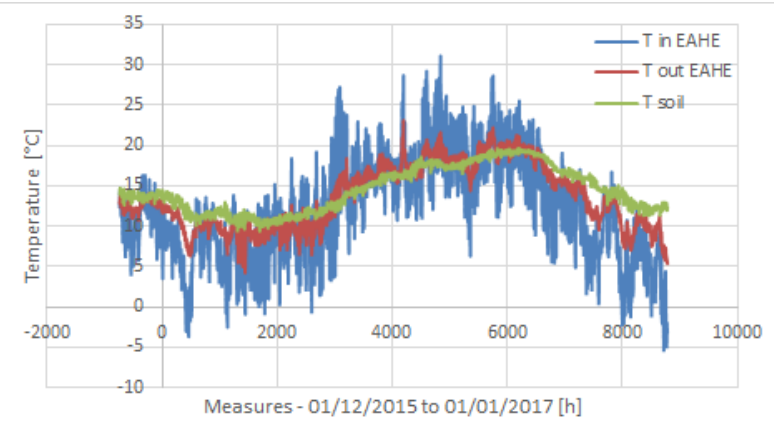

Figure 3: Soil temperature measured at $2 m$ depth and EAHE inlet and outlet temperatures during the period from 01/12/2015 to 01/01/2017.

\section{EAHE models}

There are different models of EAHE in the literature. Some analytical or numerical models have been validated by experimental measurements (Kaushal, 2017). Other models have been developed to define simple sizing rules (Hollmuler, 2002) which defines thumb rules for defining the damping of the daily or annual oscillation.

The models studied here were realized using the COMSOL Multiphysics and MATLAB software. The COMSOL Multiphysics software is used to realize numercial's simulations with the finite element method. It has several basic physical interfaces that can be combined to solve Multiphysics's problems.

The mesh can be defined manually, automatically or semi-automatically and several methods are available.

\section{D numerical model developed}

To facilitate simulations, simplifying assumptions have been made. The first is to neglect the vertical parts of EAHE because the heat exchange is low given the large internal diameter and low air speeds. The second is to consider the well as straight and not to consider the elbows.

To validate these simplifying hypotheses, two 3D models have been realized, Figure 4. A first complete model does not consider the simplifying assumptions and a second model to consider them.
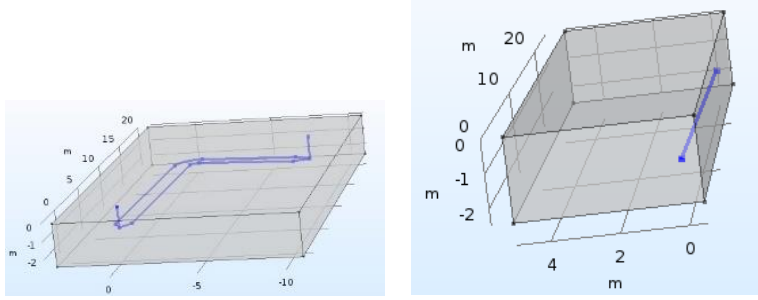

Figure 4: Full-scale 3D model and simplified 3D model.

The temperature of the soil matrix was defined as being equal to the soil temperature at a depth of $2 \mathrm{~m}$ on December 1, 2014 or 2015, date of the beginning of simulation. It is therefore $15.2{ }^{\circ} \mathrm{C}$ (year 2015) and $14{ }^{\circ} \mathrm{C}$ (year 2016).

At the interface between the ground and the external environment, the energy conservation is expressed in the form:

$\vec{n} \cdot(k \cdot \vec{\nabla} T)=\varphi+h_{\text {surface }}\left(T_{\text {ext }}-T\right)+\varepsilon \sigma\left(T_{a m b}^{4}-T^{4}\right)$

To simplify the model, the temperature $\mathrm{T}_{\mathrm{amb}}$ is assimilated to the temperature $T_{\text {ext }}$. Along the water table, the Dirichlet condition is considered. The imposed temperature has been defined as the arithmetic mean of the outside temperatures. In 2015 , it was $12.5{ }^{\circ} \mathrm{C}$ and in 2016 , it was $11.9^{\circ} \mathrm{C}$. To the simplified model, a symmetry condition is used to limit the simulation at one pipe. The inside of the tube is modelled by the physics 'heat transfer in pipes' which considers an internal film resistance characterized by a Nusselt number of 3.66 (calculation of the viscous boundary layer) for the circular sections and a conductive heat transfer within the material of the pipe. The thickness of the pipe is $1 \mathrm{~mm}$ and its conductivity (k) is $0.49 \mathrm{~W} . \mathrm{m}^{-1} \cdot \mathrm{K}^{-1}$.

\section{Pseudo-3D numerical model developed}

In the pseudo-3D model, the EAHE is discretized over its length in different parts called sections (Tittelein, 2008). The heat transfer between the soil and the interior air of the EAHE is considered uniform within the section and is calculated in the normal plane to the tube (2D inlet of the section).

For a simplified approach of the temperature field in the soil, a pure conductive model is acceptable.

After having analysed both 3D models, we have shown that the vertical parts of the EAHE, with a large internal diameter of $375 \mathrm{~mm}$, have a very limited impact on the global heat transfer. So, they are not integrated in the pseudo-3D model

The initial condition is identical to the one of the $3 \mathrm{D}$ models.

The boundary conditions of the pseudo-3D model are identical to those of the 3D models except for the inside of the pipe. For this boundary, at first, only convective heat transfer has been considered. This corresponds to a Fourier condition. In a second time, the phenomenon of condensation is taken into account and a Neumann condition will be added. The energy balance on this boundary is then expressed as follows: 


$$
\vec{n} \cdot(k \cdot \vec{\nabla} T)=\underbrace{h_{\text {tube }} \frac{c_{a}}{c_{H}}\left(T_{\text {air }}-T_{\text {wall }}\right)}_{\text {Fourier condition }}+\underbrace{\varphi_{0}}_{\begin{array}{c}
\text { Neumann } \\
\text { condition }
\end{array}}
$$

We take an average value $T_{\text {wall,m }}$ to evaluate the mean heat transfer coefficient. Knowing the air temperature and its speed, the mean wall temperature, we evaluate Re, Pr and $\mathrm{Nu}$ numbers to determine the convective heat transfer coefficient between the air located in the section and the inner wall of the pipe.

$\mathrm{f}$ and $\mathrm{Nu}$ have been calculated with the Gnielinski's formula, (Mills, 1992):

$$
f=(0,790 \cdot \ln R e-1,64)^{-2}
$$

for smooth tube

$$
N u=\frac{\frac{f}{8} \cdot(R e-1000) \cdot P r}{1+12,7 \cdot\left(\frac{f}{8}\right)^{\frac{1}{2}} \cdot\left(\operatorname{Pr} r^{\frac{2}{3}}-1\right)}
$$

$$
\text { for }\left[\begin{array}{c}
0,5<P r<2000 \\
2300<\operatorname{Re}<5.10^{6}
\end{array}\right]
$$

To determine if there is condensation, the $\mathrm{x}$ of air entering the section is compared to the $\mathrm{x}_{\mathrm{sat}}$ for the $\mathrm{T}_{\text {wall,m }}$ at each time step. If $\mathrm{x}$ is greater than $\mathrm{x}_{\text {sat }}$, there is condensation and $\varphi_{0}$ must be determined.

$$
\begin{gathered}
\varphi_{0}=\frac{h_{\text {tube }}}{c_{H}} \cdot\left(c_{v} \cdot\left(x \cdot T_{\text {air }}-x_{\text {sat }}\left(T_{\text {wall }, m}\right) \cdot T_{\text {wall }, m}\right)+\right. \\
\left.L_{c} \cdot\left(x-x_{\text {sat }}\left(T_{\text {wall }, m}\right)\right)\right)
\end{gathered}
$$

The integration along the tube for the pseudo-3D model with condensation is solved with the algorithm represented on Figure 5.

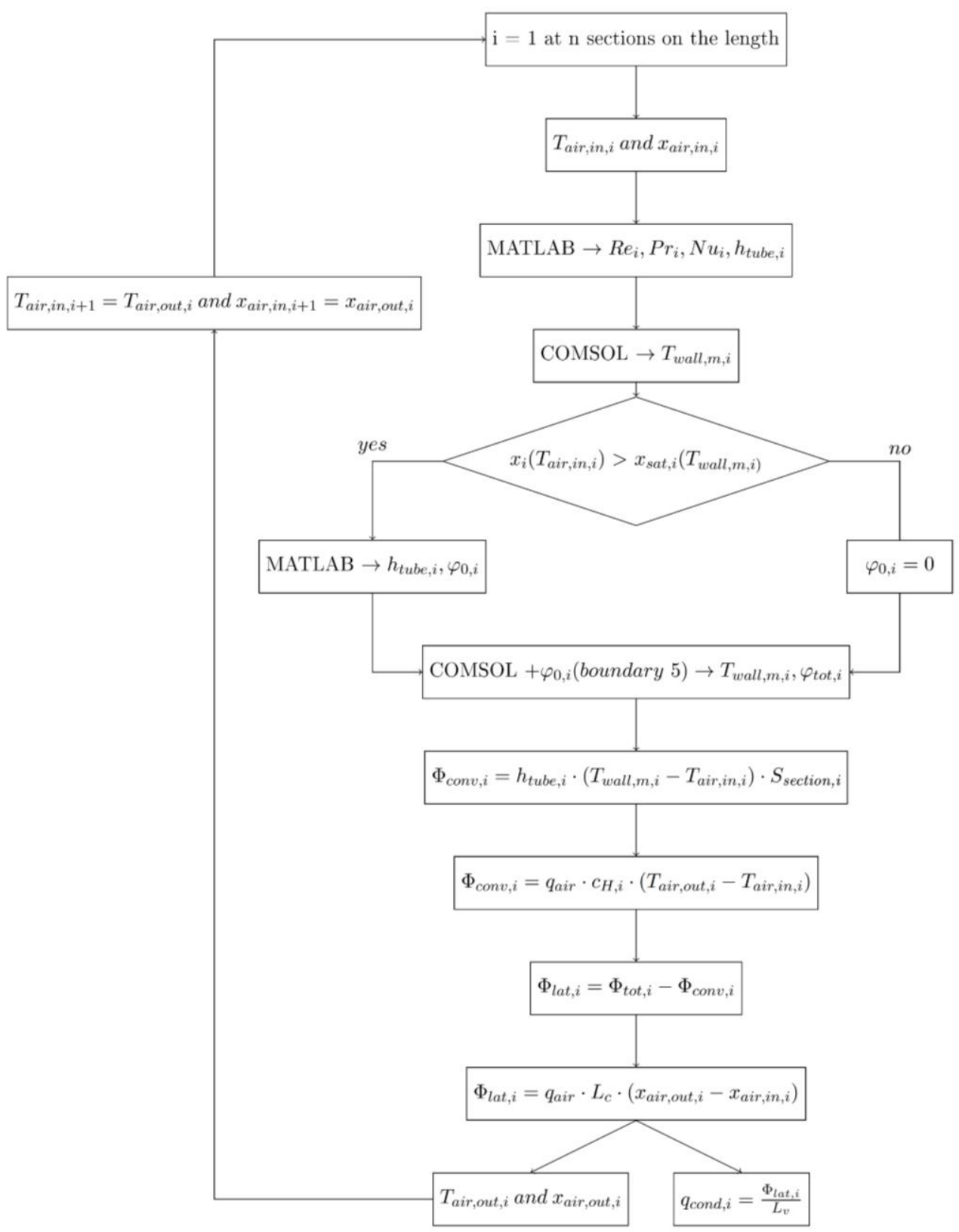

Figure 5: Algorithm for solving the unsteady pseudo-3D problem considering the condensation. 


\section{Results and discussion}

Based on the average of the absolute errors, $\epsilon_{a}$ is calculated according to the formula:

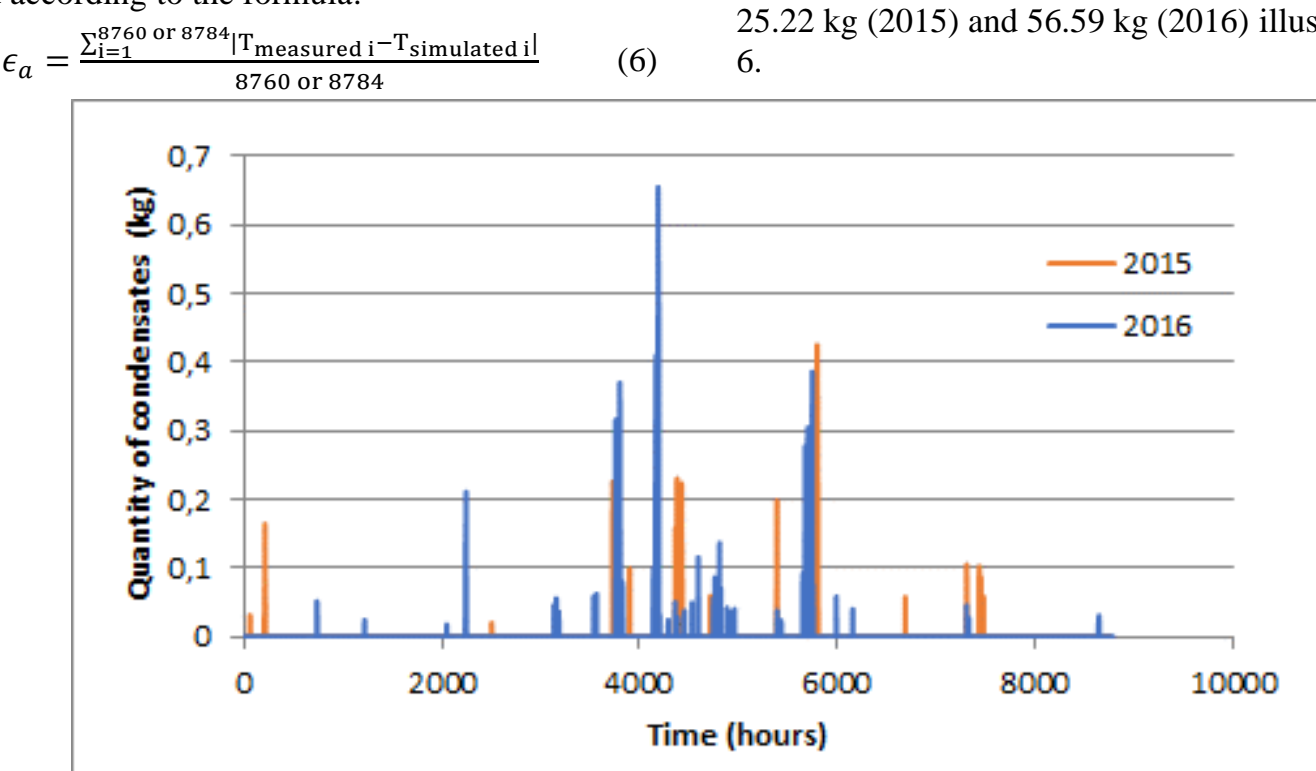

Figure 6: Quantity of condensates produced in one of the two tubes - results of the pseudo-3D model.

Considering the condensation does not significantly impact the results of the simulations. This is due to the small amounts of condensate produced and the difference in production is related to the higher air humidity in 2016.

Peaks of production occur during particularly hot and humid stormy days like in June 2016.

In Figures 2 and 3, we can see that the outlet temperatures of the EAHE are between 3 and $23^{\circ} \mathrm{C}$, the condensates being at similar temperatures, the risk of development of microorganisms is present. We can also see the positive effect of the well on the preheating and cooling of the hygienic ventilation air.

Considering that it is necessary to heat if the outside temperature is below $18{ }^{\circ} \mathrm{C}$ and to cool if the outside temperature is higher than $22{ }^{\circ} \mathrm{C}$, the energy savings can be calculated according to the formulas:

Heating energy saved :

$$
\begin{aligned}
& Q=\sum_{T_{\text {air }, \text { in }<18^{\circ} \mathrm{C}}} q_{\text {air }} \cdot c_{\text {air }} \cdot\left(T_{\text {air }, \text { out }}-T_{\text {air }, \text { in }}\right) \cdot \Delta t \\
& \text { Cooling energy saved: } \\
& Q=\sum_{T_{\text {air }, \text { in }}>22^{\circ} \mathrm{C}} q_{\text {air }} \cdot c_{\text {air }} \cdot\left(T_{\text {air }, \text { in }}-T_{\text {air }, \text { out }}\right) \cdot \Delta t
\end{aligned}
$$

The heat gain for 2015 is $1655 \mathrm{kWh}$ and $1822 \mathrm{kWh}$ for 2016. The heat loss is $146 \mathrm{kWh}$ for 2015 and $190 \mathrm{kWh}$ for 2016.

\section{Indoor Air Quality}

All buildings with human activity must be ventilated to guarantee the indoor air quality. To ensure this ventilation and to allow the preheating of the air or its cooling, an EAHE can be installed (Leo Samuel, 2017).

It is therefore legitimate to wonder if the fact of passing the air necessary for this ventilation through a buried pipe is not likely to increase the presence of pollutants or, to reveal other that would have developed within the pipe.
The result obtained for the pseudo-3D model integrating condensation is an absolute error of $0.72 \mathrm{~K}(2015)$ and $0.96 \mathrm{~K}(2016)$. The quantity of condensates produced is $25.22 \mathrm{~kg}(2015)$ and $56.59 \mathrm{~kg}$ (2016) illustrated in Figure 6.
EAHE has minimal impact on the air humidity entering the building. It slightly decreases the absolute humidity of the air in the summer period given the condensation of moisture contained in the air within the pipe and just slightly increases the absolute humidity of the air after the summer period. In fact, the condensates produced in the summer period agglomerate in the pipe in liquid form but after this period, they evaporate.

Radon is a radioactive gas formed by Uranium 238 naturally present in the soil and rocks. To avoid contamination, an EAHE must be perfectly sealed and the air inlet must be at least one metre above the ground.

The air intake of EAHE must also be located outside any source of pollution and the pipe material must be completely inert to avoid contamination of the air with physical agents (PM) or chemical agents (VOCs, $\mathrm{CO}_{2}$, etc.).

Pollution from biological agents is more difficult to avoid. Pollutants of biological origin can be divided into several categories: pollen, moulds with their mycotoxins and bacteria with their toxins. They are responsible for three negative impacts on health:

- Infectious effect: diseases caused by the intrusion of moulds or bacteria into the body;

- The toxic effect: adverse effects on the body caused by the physicochemical properties of moulds and bacteria;

- The allergenic effect: it can be caused by moulds, bacteria and pollen.

Biological agents can contaminate the ventilation air by being present at the air intake but also by developing within the pipe, especially in liquid condensates.

The filtration system has an effective role against mould but can also be a place conducive to their development (Déoux, 2011). For the bacterial load, some 
microorganisms that were not present in the outside air, were found at the exit of EAHE which proves that a development of microorganisms therefore takes place well within the pipe. Maintenance and regular replacement of the filtration system is therefore necessary, as well as cleaning of the pipe at the end of the summer period.

\section{Measurement campaign}

The EAHE studied was also analysed from a biological point of view using a specialized institution, Hainaut Vigilance Sanitaire, located in Mons, Belgium (Jellad, 2011).

Samples took place on several dates in 2011 and under very specific conditions shown on Table 2.

Table 2: Month and conditions of the campaigns.

\begin{tabular}{|l|c|c|c|c|}
\hline & Month & $\begin{array}{c}\mathrm{T} \text { in } \\
\mathrm{EAHE} \\
{\left[{ }^{\circ} \mathrm{C}\right]}\end{array}$ & $\begin{array}{c}\mathrm{RH} \text { in } \\
\text { EAHE } \\
{[\%]}\end{array}$ & $\begin{array}{c}\mathrm{T} \text { out } \\
\text { EAHE } \\
{\left[{ }^{\circ} \mathrm{C}\right]}\end{array}$ \\
\hline Campaign 1 & March & 7 & 39 & 9 \\
\hline Campaign 2 & April & 23.7 & 27 & 11.9 \\
\hline Campaign 3 & May & 21 & 40 & 16.5 \\
\hline
\end{tabular}

Each sampling campaign is done in three different places:

- at the air intake of the EAHE to serve as a reference for the content in the outside air-Site 1 ;

- in a chamber located at the exit of the EAHE but before entering the mechanical ventilation filtration system - Site 2;

- After passing through the filtration system of mechanical ventilation - Site 3 .

To ensure the proper production of the culture medium, a blank culture medium, not exposed (NE) to the air was also studied.

Two devices were used for sampling the air. First, the aero bio collector 'Air Ideal' that quantifies the presence of bacteria, yeasts and moulds and sucks 80 liters of air per measurement. Secondly, the RCS ${ }^{\circledR}$ High Flow quantifies the presence of yeast and mould and sucks 100 liters of air per measurement.

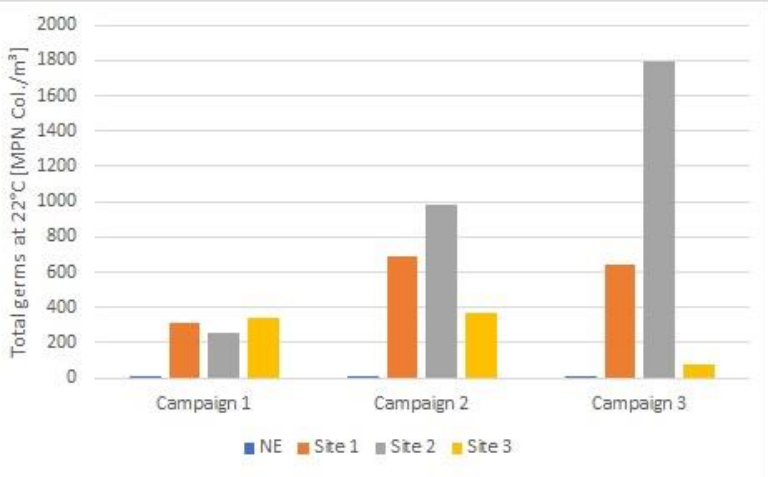

Figure 7: Results of campaign measures with the aero bio collector 'Air Ideal'.

The measurements illustrated in Figure 7 are expressed in total germs, ie all the microorganisms present in the volume of air sampled. The unit is the 'MPN Col. $/ \mathrm{m}^{3}$ ' which represents the most probable number of germs collected per $\mathrm{m}^{3}$. These samples show the presence of yeasts, bacteria and moulds. Since no yeast and few bacteria have been detected, this means that the results almost exclusively apply to the amount of mould present. Since the campaigns 1 and 2 were carried out outside the period of appearance of the condensates in the pipe, the results did not show a significant increase in the microbial load. By contrast, campaign 3 showed a significant increase in the microbial load, mainly of the mould type at the outlet of the pipes before passing through the filtration system.

To complete this study, two measurement campaigns with microbiological metagenomic analyse are planned for the installation.

\section{Conclusion}

A pseudo-3D numerical model considered the condensation phenomena in EAHE could be established and validated by comparing the results of the simulations with the experimental data. To limit the calculation time, simplifying hypotheses have been defined and verified by comparing the results of the pseudo-3D numerical model to complete or simplified 3D models.

The potential for preheating and cooling the air of EAHE could be analysed and energy savings quantified over two years, showing the interest of this technique.

The presence of a well-designed and maintained EAHE does not represent a risk to human health, but microorganisms can grow there. Although the filtration system seems sufficient to eliminate the risk associated with these microorganisms, a filter failure cannot be ruled out, which is why a more in-depth study of the microorganisms developing in the pipe is underway.

\section{Nomenclature}

$\rho$

specific heat capacity, $\mathrm{J}_{\mathrm{kg}}{ }^{-1} \cdot \mathrm{K}^{-1}$

density, $\mathrm{kg} \cdot \mathrm{m}^{-3}$ thermal conductivity, $\mathrm{W} \cdot \mathrm{m}^{-1} \cdot \mathrm{K}^{-1}$ emissivity temperature, ${ }^{\circ} \mathrm{C}$ heat flux, W. $\mathrm{m}^{-2}$ convective heat transfer coefficient, $\mathrm{W} \cdot \mathrm{m}^{-2} \cdot \mathrm{K}^{-1}$ Stefan-Boltzmann constant, $5,67 \cdot 10^{-8} \mathrm{~W} \cdot \mathrm{m}^{-2} \cdot \mathrm{K}^{-4}$ specific heat capacity of dry air, $\mathrm{J}^{\mathrm{kg}}{ }^{-1} \cdot \mathrm{K}^{-1}$ specific heat capacity of moist air, $\mathrm{J}^{\mathrm{kg}} \mathrm{kg}^{-1} \cdot \mathrm{K}^{-1}$ Reynolds number Prandtl number Nusselt number friction factor specific heat capacity of water vapor, $\mathrm{J}^{\mathrm{kg}}{ }^{-1} \cdot \mathrm{K}^{-1}$ humidity ratio, $\mathrm{kg}_{\text {water }} \cdot \mathrm{kg}_{\text {dry air }}^{-1}$ saturation humidity ratio, $\mathrm{kg}_{\mathrm{water}} \cdot \mathrm{kg}_{\mathrm{dry}}^{-1}$ air

$\mathrm{L}_{\mathcal{c}} \quad$ latent heat of condensation, J.kg ${ }^{-1}$

$\Phi \quad$ heat flow, $\mathrm{W}$ 
$\mathrm{S} \quad$ surface, $\mathrm{m}^{2}$

q mass flow, kg.s ${ }^{-1}$

$\mathrm{e}_{\mathrm{a}} \quad$ absolute error on temperature, $\mathrm{K}$

$\mathrm{RH}$ relative humidity

Q energy, J

$\Delta \mathrm{t} \quad$ time step, $\mathrm{s}$

\section{References}

Barbat M. (2012). Nettoyabilité des puits climatiques. Scientific report, Costic.

Bordoloi N., Sharma A., Nautiyal H., Goel V. (2018). An intense review on the latest advancements of earth air heat exchangers. Renewable and Sustainable Energy Reviews (89), 261-280.

Chardome G. \& Feldheim V. (2018) Transferts de chaleur et condensation au sein d'un échangeur air-sol : modélisations numériques 2D/3D validées par des relevés expérimentaux. Proceedings from SFT2018: Société Française de Thermique Conference. Pau (FR), 29 May 2018 - 01 June 2018.

Déoux S. (2011). Mission d'évaluation sanitaire du puits canadien - Siège social du Groupe Millet. Scientific report 'Analyse Qualité Santé AQS®', Medieco.

Fisk W. (2002). How IEQ affects health, productivity, ASHRAE Journal (44), 56-60.

Hollmuller P. (2002), Utilisation des échangeurs air/sol pour le chauffage et le rafraîchissement des bâtiments. PhD Thesis Faculty of Science-University of Geneva.
INISMa - Institut Interuniversitaire des Silicates, Sols et Matériaux (2011). Reconstruction $d u$ pertuis $d u$ trouillon entre la rue valenciennoise et l'avenue maistriaux. Campagne géotechnique. Technical report.

Jellad M. (2011). Impact éco-énergétique et sanitaire d'un puits canadien sur une habitation ossature bois. Master's thesis, ISIMs - Campus Technique de la Haute Ecole en Hainaut.

Jomehzadeh F. (2017). A review on windcatcher for passive cooling and natural ventilation in buildings, Part 1: Indoor air quality and thermal comfort assessment. Renewable and Sustainable Energy Reviews (70), 736-756.

Kaushal M. (2017), Geothermal cooling/heating using ground heat exchanger for various experimental and analytical studies: Comprehensive review. Energy and Buildings (139), 634-652.

Leo Samuel D. G. (2017), Cooling Performance and Indoor Air Quality Characteristics of an Earth Air Tunnel Cooled Building. Journal of Metrology Society of India MAPAN (33), 147-158.

Mills A.F. (1992). Heat Transfer, McGraw-Hill Inc., US, 270.

Ozgener L. (2011). A review on the experimental and analytical analysis of earth to air heat exchanger (eahe) systems in turkey. Renewable and Sustainable Energy Reviews (15), 4483-4490.

Wargocki P. (2011). Productivity and health effects of high indoor air quality. In Encyclopedia of environmental health, Elsevier, 688-693. 